\title{
Do seriously offending girls differ from their age- and offence type-matched male counterparts on psychopathic traits or psychopathy-related background variables?
}

\author{
Nina Lindberg ${ }^{1,7^{*}}$, Svetlana Oshukova ${ }^{2}$, Jouko Miettunen ${ }^{3,4,5}$ and Riittakerttu Kaltiala-Heino ${ }^{6,8}$
}

\begin{abstract}
Background: More research is needed to improve our understanding of the manifestation of psychopathic traits in violently offending girls. Our aim here was to assess psychopathic traits and psychopathy-related background variables in a Finnish nationwide consecutive sample of girls charged with violent crimes and referred to a pretrial forensic psychiatric examination. These girls were then compared to their male counterparts.
\end{abstract}

Methods: The forensic psychiatric examination statements of 15- to 17-year-old juveniles who underwent a pretrial forensic psychiatric examination over a 31-year period (1980-2010) were reviewed. For each non-psychotic girl with a normal IQ $(n=25)$, an age- and offence type-matched male control was randomly selected. Offence and offender characteristics were collected from the forensic psychiatric examination reports, and a file-based assessment of psychopathic traits was performed using the Hare psychopathy checklist-youth version.

Results: Approximately every third girl exhibited high traits of psychopathy, and no significant difference was observed between the genders. Focusing on the underlying factor and item scores, the girls scored significantly lower than boys on the Antisocial factor. Their interpersonal relationships were significantly more unstable and they significantly more often exhibited a history of child sexual abuse. During the index offence the girls were significantly less frequently intoxicated, and their victims were significantly more often family members or current or ex-intimates but significantly less often strangers.

Conclusions: Although violently offending girls and boys do not differ on psychopathy total scores, significant gender differences exist on underlying factor and item scores as well as in background- and offence-related variables. Interventions should take into account these special features of violent girls.

Keywords: Adolescence, Delinquency, Gender, Girl, Offending, Psychopathic traits

\section{Background}

A personality trait is a fairly stable way of experiencing and perceiving oneself as well as perceiving and relating to others. Psychopathy is a constellation of interpersonal (dishonest charm, grandiosity, lying, and manipulative behavior) affective (remorselessness, unemotionality, and callousness) and behavioral (thrill-seeking, impulsivity,

\footnotetext{
*Correspondence: nina.lindberg@hus.fi

${ }^{7}$ Kellokoski Hospital, Vanha Valtatie 198, 04500 Kellokoski, Finland Full list of author information is available at the end of the article
}

and irresponsibility) traits [1]. Current conceptualizations see psychopathic traits on a dimensional continuum, where psychopathy is a malicious version of the extremes of normal personality traits [2]. In 2013, a subtype of conduct disorder characterized by callousunemotional traits was introduced in the fifth version of the diagnostic and statistical manual of mental disorders (DSM 5) [3]. The specifier "with limited prosocial emotions (LPE)" is used when an individual, suffering from conduct disorder, exhibits two or more of the following characteristics in multiple relationships or settings over 
a 12-month period: (1) lack of remorse or guilt, (2) callousness/lack of empathy, (3) shallow or deficient affect, and (4) unconcern about his/her performance. Psychopathic traits are relatively stable over time, from childhood through adolescence to adulthood $[4,5]$. On the other hand, traits can change across favorable development and treatment [6]. Research findings on gender differences in psychopathic traits in adolescence are mixed, with some studies reporting overall higher psychopathic tendencies among boys than among girls, and others finding no gender difference [7]. Higher psychopathy scores for boys than for girls tend to emerge in samples recruited from community settings, while studies among institutionalized youth have reported fewer differences in psychopathic scores across the genders [7]. Evidence also indicates different expression of psychopathy in girls and boys where, among girls, the interpersonal and affective features more clearly capture psychopathy than do the behavioral ones [8].

In light of current literature, psychopathy is strongly associated with genetic and neurobiological background [9], but also environmental factors seem to have an influence on its development [10]. Broken families, institutional or foster home placements, low parental care, harsh discipline, physical and psychological abuse, parents' antisocial and criminal behavior, parents' mental health and substance use problems, delinquent siblings, large family size, school difficulties, and mental health problems in childhood and/or adolescence are all associated with elevated psychopathic traits [11-16]. The literature suggests that there are differences in the origins of and developmental pathways to psychopathy between the genders [17]. Evidence supports a lower heritability of psychopathic traits [18-20] as well as a greater role of family-related risk factors in girls than in boys [21]. However, according to a recent study by Ficks et al. [22], the etiology of psychopathic traits in youth seems to be highly similar for girls and boys.

Juvenile psychopathy is becoming an increasingly important construct in judicial systems [17]. Offenders with strong psychopathic traits typically begin their antisocial and criminal activities at a relatively young age and continue to engage in these activities throughout their lifespan [23]. In addition, their use of violence tends to be more instrumental, dispassionate, and predatory than that of other offenders [24]. They also re-offend more quickly and more often following release from custody than do other offenders [25, 26]. Elevated traits of psychopathy relate to severity of violence [27], and affective-interpersonal features of psychopathy predict more frequent use of sadistic violence, repeated violence against the same victim, and violence resulting in more serious victim injuries [28]. Psychopathic traits associate with a greater likelihood of an adolescent to offend in groups and to be in a gang, as well as to take a leadership role in group crimes [29].

The number of studies focusing on psychopathic traits in offending girls is limited, most probably due to the small number of female offenders overall $[30,31]$, yet they seem to represent a growing population [32]. In a study by Schrum and Salekin [8] among 123 girls aged 11-18 years from two American detention centers, as many as $16.9 \%$ exhibited significant traits of psychopathy (the psychopathy checklist-youth version [PCLYV] $\geq 25$ ). In a study by Campbell et al. [33] among 226 Canadian incarcerated 12- to 19-year-old youngsters (girls: $17 \%$ ), girls and boys did not significantly differ from each other in psychopathic traits. In this sample, the most frequent convictions in both genders were non-violent offences $(86 \%)$ and the base rate of high psychopathic traits (PCL-YV $\geq 25$ ) was relatively low (9.4\%). Accordingly, no gender difference was reported by Salekin et al. [34] among 114 children and adolescents (girls: $29.8 \%$ ) recruited from an American detention center. The crimes of these youngsters included mainly thefts, assaults, and other violent offences. However, in a German sample of 90 incarcerated boys and 123 girls aged 14- to 19 years, boys exhibited significantly higher traits of psychopathy (both total and underlying factor scores) than did girls [35]. In this sample, $71.6 \%$ of the adolescents had been convicted of at least one violent criminal act. With regard gender differences, $36.3 \%$ of the detained girls had never been convicted of a violent crime versus only $20.2 \%$ of the boys. Further, in a Canadian sample of 142 youngsters ( 76 boys and 66 girls) aged 12 - to 18 years, who had been actively involved in the local criminal justice system and/or who had been diagnosed as having a severe conduct disorder, boys exhibited significantly higher affective-interpersonal traits of psychopathy than did girls, but no gender difference was observed on the behavioral component of psychopathy [36]. In this sample, the vast majority (96\%) reported being involved in at least one violent act in the course of their lives. Girls reported engaging in significantly fewer types of violent crimes than did boys. With regard to non-violent offences, no statistically significant gender difference was observed.

To summarize, there is a need for further research to improve our understanding of the manifestation of psychopathic character traits in offending girls. The aim of this study was to assess psychopathic traits as well as psychopathy-related background variables in a Finnish nationwide sample of juvenile girls charged with violent offences and referred to a pretrial forensic psychiatric examination and to compare these girls with their ageand offence-matched male counterparts. Our hypotheses 
were that we would find a subgroup of girls exhibiting high traits of psychopathy and that the gender differences would be minimal in this special population of highly violent underaged criminals.

\section{Sample and methods}

\section{Sample and procedure}

Information was obtained from the National Institute of Health and Welfare, which organizes the forensic psychiatric examinations in Finland. According to Finnish law, courts decide whether a forensic examination is needed. After deciding on the examination, the court asks the National Institute of Health and Welfare to arrange it. Forensic psychiatric examinations are inpatient evaluations lasting approximately 2 months, and include data gathered from various sources (family members, relatives, and medical, criminal, school, child welfare, and military records), psychiatric evaluation, standardized psychological tests, interviews conducted by a multiprofessional team, evaluation of the offender's physical condition, and continuous observation of the offender by hospital staff. The final forensic psychiatric report includes an opinion on the level of criminal responsibility, a possible psychiatric diagnosis, and an assessment as to whether or not the offender fulfils the criteria for involuntary psychiatric care. The overall quality and reliability of Finnish forensic psychiatric examinations are considered high by both courts and scientists [37]. In Finland, psychiatric classification according to the International Classification of Diseases-Eighth Revision (ICD-8) [38] served in clinical practice between 1968 and 1986 and was replaced by the diagnostic and statistical manual of mental disorders, third edition, revised (DSMIII-R) [39], which was used between the years 1987 and 1995. Since 1996, ICD-10 [40] has been in use.

In Finland, the minimum age of criminal liability is 15 years. As part of a large research project on Finnish juvenile pretrial offenders, forensic psychiatric examination reports of all 15- to 17-year-old offenders who underwent the examination in 1.1.1980-31.12.2010 were collected from the archives of the National Institute of Health and Welfare. Forensic psychiatric examination reports were retrospectively reviewed. The study protocol was approved by the Ethics Committee of Helsinki University Hospital and the pertinent institutional authorities.

\section{Assessment of psychopathic traits}

The psychopathy checklist-youth version (PCL-YV) [41], which is an adaptation of the psychopathy checklist-revised (PCL-R) [42], was used to assess psychopathic traits. Each of the 20 PCL-YV items is rated as 0 (absent), 1 (present to some degree or contradictory data), 2 (definitely present), or omitted if the information was insufficient. To aid in the scoring and determination of each trait, the manual provides an item description and some behavioral examples [41]. An individual's assessment is rejected if it contains more than five omitted items [41]. The total score can range from 0 to 40, with higher scores reflecting a greater number of psychopathic traits. The total PCL score is dimensional, but in research settings categorical diagnoses are used as well. There is no recommended cut-off score for use with the PCL-YV, but on the PCL-R total scores ranging from 30 to 40 are considered diagnostic of psychopathy [43]. In line with recommendations of a lower cut-off score for European populations [44-46], a cut-off score of 25 has been used in studies performed in Scandinavian countries [47-49] and a score of 20 is sometimes considered to be a cut-off for "medium psychopathy" [50]. The PCL-YV items can be summed to yield four factors: factor I or the interpersonal factor (items: impression management, grandiose sense of self-worth, pathological lying, manipulation for personal gain), factor II or the affective factor (items: lack of remorse/guilt, shallow affect, callous/lack of empathy, failure to accept responsibility), factor III or the behavioral factor (items: stimulation-seeking, parasitic orientation, lack of goals, impulsivity, irresponsibility), and factor IV or the antisocial factor (items: poor anger control, early behavior problems, serious criminal behavior, serious violation of conditional release, criminal versatility). Although PCL assessments should be based on both a review of file information and a semi-structured interview, several studies have shown that PCL assessments can reliably be made for both adults [51-54] and adolescents $[28,55-58]$ without the interview when sufficient file information is available. In this study, the scoring was done by one officially trained female rater (NL). After this, 20 (40\%) reports were randomly chosen and rated by one independent male rater to assess inter-rater reliability. The inter-rater agreement was assessed using intraclass correlation (ICC). The ICC was 0.886 for PCLYV total score, 0.748 for factor 1 score, 0.890 for factor 2 score, 0.868 for factor 3 score and 0.844 for factor 4 score. All correlations were significant $(\mathrm{p}<0.001)$. The internal consistency, as measured by Cronbach's alpha, was 0.89 for all items, 0.86 for factor 1 , and 0.79 for factor 2, 0.84 for factor 3 , and 0.74 for factor 4 .

\section{Offender- and offence-related variables}

Data on demographics, family-related characteristics [parents' divorce, parental psychiatric and substance use problems, family size (more than four children in the family), institutional/foster home placements, criminality of near relatives], problems related to school (failure to pass grade in primary/secondary schools, attending 
special education), psychiatric (mental health contacts), social (client of social services, witnessing/subject of physical violence at childhood home, sexual abuse), and criminal history (previous non-violent and violent offending and the index offence (intoxication, more than one victim, more than one offender, victim-offender relationship [family or (ex-)intimate, acquaintance, stranger], signs of instrumental violence were gathered from the forensic psychiatric evaluation reports. All items were rated categorically as 1 (=present) or 0 (=absent). After one rater (NL) had coded all the cases, 20 (40\%) randomly selected reports were coded by an independent male rater in order to ensure that variables were unambiguous enough to guarantee reliable subjective interpretations of their presence/absence. Interrater agreement was assessed using Cohen's kappa ( $\mathrm{k}$ ) [59]. According to the Landis and Koch guidelines [60], all variables showed substantial (0.61-0.80) or almost perfect (0.81-1) agreement.

\section{Statistical analysis}

We conducted a multivariate analysis (MANOVA) across the four factors of the PCL-YV. We continued with the Independent samples $\mathrm{t}$ test, the Likelihood ratio Chi square test, and Fisher's exact test to compare the groups. Findings were considered significant when $\mathrm{p}<0.05$. The phi $(\phi)$ coefficient was used as an effect size measure for the Chi square test, and Cohen's d for the Independent samples $t$ test. The magnitude of the $\phi$ coefficient was interpreted as follows: 0.1 as small, 0.3 as moderate, and 0.5 as large effect, and respectively, Cohen's $d$ as follows: 0.2 as small, 0.5 as moderate, and 0.8 as large effect [61]. We conducted data analyses with the SPSS statistical software package version 22 .

\section{Results}

During the study period altogether 266 adolescents aged 15-17 years underwent a forensic psychiatric examination, 29 (10.9\%) of whom were girls. Of these juveniles, 4 girls and 21 boys suffered from intellectual disability or a current psychotic disorder (mainly schizophrenia) and were excluded from further analyses since it is questionable whether a youngster with abnormally low IQ or acute symptoms of psychosis can be scored with the PCL-YV. The remaining 25 girls with a mean age of 16.3 (SD 0.74) years were all native Finns and charged with violent offences, including murder $(\mathrm{n}=5)$, attempted murder $(\mathrm{n}=4)$, manslaughter $(\mathrm{n}=2)$, attempted manslaughter $(\mathrm{n}=7)$, aggravated assault $(\mathrm{n}=2)$, arson $(\mathrm{n}=3)$, and violent robbery $(\mathrm{n}=2)$. Nineteen $(76.0 \%)$ of them showed a history of previous offending and $8(32.0 \%)$ had a history of violent offending (mainly assaults) before the index crime. Twenty ( $80 \%)$ girls had been arrested before the index offence, but none of them had been imprisoned. Most girls were diagnosed with a conduct disorder or a personality disorder $(n=21)$, but four girls had no mental disorder. For each girl, an age- and offence typematched male control of Finnish origin was randomly selected from the national data.

The comparisons between girls and boys are presented in Table 1. Approximately every third girl exhibited significant (PCL-YV $\geq 25$ ) psychopathic traits, and no significant difference was observed between the genders. MANOVA revealed significant gender differences in factor structure (Wilk's $\Lambda=0.733, \mathrm{~F}(4.45)=4.10$, $\left.p=0.006, \eta^{2}=0.27\right)$. Girls scored significantly lower on the antisocial factor, including poor anger control, early behavioral problems, and criminal versatility, than boys. Girls also scored lower on stimulation-seeking, impulsivity, and irresponsibility, which load onto the Behavioral factor. There was a tendency for girls to score higher on the affective factor, but the difference did not reach statistical significance. Girls scored significantly higher on the item "unstable interpersonal relationships", and they also showed a tendency to score higher on the item "Impersonal sexual behavior".

With regard to background variables, girls had been significantly more often sexually abused as children than boys. There was also a tendency for girls to more often have been subjects of physical violence in the childhood home. With regard to offender- and offence-related variables, girls were significantly less often intoxicated during the index offence, and their victims were significantly more often family members or current or ex-intimates but less often strangers.

\section{Discussion}

An important question is if, and if so, to what extent psychopathic traits manifest differentially as a function of gender. In this nationally representative sample of highly violent adolescents, girls and boys who had committed comparable crimes were also comparable regarding their psychopathic traits; about two-thirds of both genders exhibited elevated psychopathic traits and one-third showed high traits of psychopathy. This is in line with the findings reported by Campbell et al. [33] and Salekin et al. [34] who found equal rates of psychopathy among incarcerated girls and boys. Our findings contradict the findings of Sevecke et al. [35] and Penney et al. [36] who reported that boys in criminal justice processes exhibited higher psychopathic trait scores than girls. In both these studies, however, boys had a history of more numerous violent offences than girls. The gender difference in severity of offending likely contributes to the differences seen on psychopathy scores, as in our sample the genders were matched for their crimes. Further reasons explaining the 
Table 1 Comparisons between a nationwide sample of girls charged with violent offences and referred to a pretrial forensic psychiatric examination $(n=25)$ and their age- and offence-matched male counterparts

\begin{tabular}{|c|c|c|c|c|c|}
\hline & Girls & Boys & Statistics $^{a}$ & p & Effect size \\
\hline \multicolumn{6}{|l|}{ PCL-YV } \\
\hline Total score mean (SD) & $19.76(8.52)$ & $20.32(6.50)$ & $t=-0.261$ & 0.795 & $d=-0.073$ \\
\hline Factor 1 (interpersonal) & $1.56(2.18)$ & $1.68(1.86)$ & $t=-0.209$ & 0.835 & $d=-0.060$ \\
\hline Factor 2 (affective) & $4.44(2.38)$ & $3.24(2.33)$ & $t=1.793$ & 0.079 & $d=0.518$ \\
\hline Factor 3 (behavioral) & $6.44(2.83)$ & $7.64(1.87)$ & $t=-1.770$ & 0.083 & $d=0.511$ \\
\hline Factor 4 (antisocial) & $5.52(2.62)$ & $6.88(1.74)$ & $t=-2.164$ & 0.035 & $d=0.624$ \\
\hline Total score $\geq 30$ & $3 / 25(12.0 \%)$ & $3 / 25(12.0 \%)$ & $\#$ & 1.000 & NA \\
\hline Total score $\geq 25$ & $8 / 25(32.0 \%)$ & $7 / 25(28.0 \%)$ & $X^{2}=0.095$ & 0.758 & $\varphi=-0.044$ \\
\hline Total score $\geq 20$ & $16 / 25(64.0 \%)$ & $14 / 25(56.0 \%)$ & $x^{2}=0.333$ & 0.564 & $\varphi=-0.082$ \\
\hline \multicolumn{6}{|l|}{ Item mean (SD) } \\
\hline Impression management & $0.44(0.58)$ & $0.48(0.51)$ & $t=-0.209$ & 0.795 & $d=0.060$ \\
\hline Grandiose sense of self-worth & $0.32(0.56)$ & $0.40(0.65)$ & $t=0.469$ & 0.641 & $d=0.135$ \\
\hline Stimulation-seeking & $1.44(0.71)$ & $1.92(0.28)$ & $t=-3.142$ & 0.003 & $d=0.907$ \\
\hline Pathological lying & $0.32(0.69)$ & $0.40(0.76)$ & $t=-0.389$ & 0.699 & $d=0.113$ \\
\hline Manipulation for personal gain & $0.52(0.77)$ & $0.36(0.70)$ & $t=0.769$ & 0.446 & $d=0.222$ \\
\hline Lack of remorse/guilt & $1.32(0.75)$ & $0.92(0.76)$ & $t=1.876$ & 0.067 & $d=0.542$ \\
\hline Shallow affect & $0.88(0.83)$ & $0.72(0.69)$ & $t=0.745$ & 0.460 & $d=0.215$ \\
\hline Callous/lack of empathy & $1.00(0.71)$ & $0.72(0.61)$ & $t=1.495$ & 0.141 & $d=0.432$ \\
\hline Parasitic orientation & $0.64(0.76)$ & $0.84(0.80)$ & $t=-0.908$ & 0.368 & $d=0.262$ \\
\hline Poor anger control & $1.36(0.70)$ & $1.84(0.37)$ & $t=-3.024$ & 0.004 & $d=0.873$ \\
\hline Impersonal sexual behavior & $0.80(0.96)$ & $0.36(0.64)$ & $t=1.912$ & 0.062 & $d=0.552$ \\
\hline Early problem behavior & $1.20(0.91)$ & $1.68(0.56)$ & $t=-2.245$ & 0.039 & $d=0.648$ \\
\hline Lack of goals & $1.52(0.71)$ & $1.40(0.76)$ & $t=0.574$ & 0.569 & $d=0.166$ \\
\hline Impulsivity & $1.56(0.71)$ & $1.92(0.28)$ & $t=-2.357$ & 0.023 & $d=0.680$ \\
\hline Irresponsibility & $1.28(0.69)$ & $1.64(0.57)$ & $t=-2.034$ & 0.048 & $d=0.587$ \\
\hline Failure to accept responsibility & $1.24(0.60)$ & $0.88(0.73)$ & $\mathrm{t}=1.915$ & 0.061 & $d=0.553$ \\
\hline Unstable interpersonal relationships & $1.00(0.96)$ & $0.28(0.61)$ & $t=3.166$ & 0.003 & $d=0.914$ \\
\hline Serious criminal behavior & $1.48(0.51)$ & $1.60(0.50)$ & $t=-0.840$ & 0.405 & $d=0.242$ \\
\hline Serious violation of conditional release & $0.48(0.65)$ & $0.32(0.48)$ & $t=0.990$ & 0.327 & $d=0.286$ \\
\hline Criminal versatility & $1.00(0.82)$ & $1.48(0.71)$ & $t=-2.213$ & 0.032 & $d=0.639$ \\
\hline \multicolumn{6}{|l|}{ Background variables } \\
\hline \multicolumn{6}{|l|}{ Childhood (0-12 years) home } \\
\hline Parents'divorce & $16 / 25(64.0 \%)$ & 17/24 (70.8\%) & $x^{2}=0.260$ & 0.610 & $\varphi=0.073$ \\
\hline Mother's substance use problems & $10 / 25(40.0 \%)$ & $5 / 25(20.0 \%)$ & $\#$ & 0.217 & NA \\
\hline Father's substance use problems & $14 / 24(58.3 \%)$ & 17/24 (70.8\%) & $X^{2}=0.820$ & 0.365 & $\varphi=0.131$ \\
\hline Mother's psychiatric problems & $5 / 25(20.0 \%)$ & $8 / 25(32.0 \%)$ & $\#$ & 0.520 & NA \\
\hline Father's psychiatric problems & $3 / 24(12.5 \%)$ & $6 / 24(25.0 \%)$ & $\#$ & 0.461 & NA \\
\hline Witnessing physical violence & $13 / 25(52.0 \%)$ & $12 / 25(48.0 \%)$ & $x^{2}=0.080$ & 0.777 & $\varphi=-0.400$ \\
\hline Subject of physical violence & $15 / 25(60.0 \%)$ & $9 / 25(36.0 \%)$ & $X^{2}=2.885$ & 0.089 & $\varphi=-0.240$ \\
\hline More than four children in the family & $11 / 25(44.0 \%)$ & 9/25 (36.0\%) & $x^{2}=0.333$ & 0.564 & $\varphi=-0.082$ \\
\hline Institutional/foster home placement & $7 / 25(28.0 \%)$ & $10 / 25(40.0 \%)$ & $X^{2}=0.802$ & 0.370 & $\varphi=0.127$ \\
\hline \multicolumn{6}{|l|}{ Other childhood (0-12 years) variables } \\
\hline Subject of sexual abuse & $9 / 25(36.0 \%)$ & 0/25 (0.0 \%) & $\#$ & 0.001 & NA \\
\hline Mental health contact & $8 / 25(32.0 \%)$ & 9/25 (36.0\%) & $X^{2}=0.089$ & 0.765 & $\varphi=0.042$ \\
\hline Client of social services & $15 / 25(60.0 \%)$ & 18/25 (72.0 \%) & $X^{2}=0.802$ & 0.370 & $\varphi=0.127$ \\
\hline \multicolumn{6}{|l|}{ Criminality of near relatives } \\
\hline Mother's criminality & $1 / 25(4.0 \%)$ & 0/25 (0.0 \%) & $\#$ & 1.000 & NA \\
\hline Father's criminality & $7 / 24(28.0 \%)$ & 8/24 (32.0\%) & $x^{2}=0.097$ & 0.755 & $\varphi=0.045$ \\
\hline
\end{tabular}


Table 1 continued

\begin{tabular}{|c|c|c|c|c|c|}
\hline & Girls & Boys & Statistics $^{\mathrm{a}}$ & p & Effect size \\
\hline Delinquent sibling/s & $8 / 25(32.0 \%)$ & $10 / 25(40.0 \%)$ & $X^{2}=0.347$ & 0.556 & $\varphi=0.083$ \\
\hline Homicide history of parents or near relatives & $5 / 25(20.0 \%)$ & $2 / 25(8.0 \%)$ & $\#$ & 0.417 & NA \\
\hline \multicolumn{6}{|l|}{ School performance in primary and secondary schools } \\
\hline Failure to pass grade at school & $14 / 25(56.0 \%)$ & $14 / 25(56.0 \%)$ & $X^{2}=0.082$ & 0.774 & $\varphi=-0.041$ \\
\hline Attending special education & $11 / 25(44.0 \%)$ & $14 / 25(56.0 \%)$ & $X^{2}=0.720$ & 0.396 & $\varphi=0.120$ \\
\hline \multicolumn{6}{|l|}{ Offence-related variables } \\
\hline History of previous offending & 19/25 (76.0\%) & $21 / 25(84.0 \%)$ & $X^{2}=0.500$ & 0.480 & $\varphi=0.100$ \\
\hline History of violent offending & $8 / 25(32.0 \%)$ & $12 / 25(48.0 \%)$ & $x^{2}=1.333$ & 0.246 & $\varphi=0.163$ \\
\hline Current alcohol use disorder & $15 / 25(60.0 \%)$ & $15 / 25(60.0 \%)$ & $X^{2}=0.000$ & 1.000 & $\varphi=0.000$ \\
\hline Intoxicated during index offence & $15 / 25(60.0 \%)$ & $22 / 25(88.0 \%)$ & $X^{2}=5.094$ & 0.024 & $\varphi=0.319$ \\
\hline More than one offender & $15 / 25(60.0 \%)$ & 10/25 (40.0 \%) & $x^{2}=2.000$ & 0.157 & $\varphi=-0.200$ \\
\hline More than one victim & $3 / 25(12.0 \%)$ & $5 / 24(20.8 \%)$ & $\#$ & 0.463 & NA \\
\hline \multicolumn{6}{|l|}{ Victim-offender relationship } \\
\hline Family or (ex-) intimate & 9/24 (37.5\%) & 0/24 (0.0\%) & $\#$ & 0.001 & NA \\
\hline Acquaintance & $11 / 24(45.8 \%)$ & $5 / 24(20.8 \%)$ & $\#$ & 0.062 & NA \\
\hline Stranger & 4/24 (16.7\%) & 19/24 (79.2 \%) & $\#$ & $<0.001$ & NA \\
\hline Index offence characterized with instrumental violence & $7 / 25(28 \%)$ & $9 / 25(36 \%)$ & $x^{2}=0.368$ & 0.544 & $\varphi=0.086$ \\
\hline
\end{tabular}

Independent samples $t$ test $(t)$, the Chi square test $\left(x^{2}\right)$, and the Fisher's exact test (\#) are used for comparing the groups. Effect sizes are reported: $d$ Cohen's $d, \varphi=$ phi Statistically significant differences are in italics

NA not applicable

different finding could be differences in psychopathology other than psychopathy, and perhaps differences in histories of subjection to abuse and trauma. So, it is obvious that the roles of psychopathology and trauma deserve further research. Our findings suggest that those girls who commit equally severe violent crimes than boys also display psychopathic traits to equal extend. Girls with less severe (violent) crimes likely display less psychopathic traits.

Even if girls and boys scored equally high on the PCLYV total scores, girls scored significantly lower than boys on the antisocial factor. There was also a tendency for girls to score higher on the affective factor and for boys to score higher on the behavioral one, although these differences did not reach statistical significance. These findings differ from those reported by Penney et al. [36], where boys scored higher on both Interpersonal and Affective factors. Penney et al. used a three-factor model of the PCL-YV, excluding largely those items that in the model used here load onto the antisocial factor. Again, the differences between Penney et al's report and ours are likely due to the fact that in their sample boys were more violent than girls.

On an item-level, boys expressed significantly higher levels of stimulation-seeking, impulsivity, and irresponsibility, as well as poor anger control, early emotional problems, and criminal versatility, reflecting an antisocial lifestyle, and, diagnostically speaking, an antisocial personality disorder, which is often diagnosed in adult male prisoners [3]. Compared with boys, girls' relationships showed significantly higher instability, which is one of the core symptoms of borderline personality, a disorder overrepresented among incarcerated women [62]. Although psychopathy is often represented as a unitary construct, it shows heterogeneity with different subtypes and multiple underlying trait dimensions. In adults, preliminary findings indicate an antisocial personality disorder variant as well as a borderline personality disorder variant of psychopathy exist, the latter being more prevalent in females [63]. Our results suggest that same kinds of gender-specific trait variations exist in adolescents. To explore this with cluster analysis methods, considerably larger sample sizes are needed. The authors are aware of one recent study focusing on latent class analyses based on self-assessed general personality traits among 12- to 17-year-old delinquents [64]. The study, based on the quick big five, suggested three personality types, consisting of an emotionally labile, close-minded and goal-oriented class, an under controlled class, and an emotionally labile-careless class. Interestingly, youngsters characterized with both emotional lability and carelessness scored highest on the externalizing behavior including rulebreaking and aggressive behavior as well as on the impulsive-irresponsible factor of the Youth Psychopathic traits Inventory. The authors, however, found no statistically significant gender differences within different personality 
classes. It is somewhat difficult to compare our results to those of Decuyper et al. [64], since Finnish forensic psychiatric statements typically include thorough descriptions of personality traits related to non-adjustment, but the descriptions of other personality traits remain often limited.

The family backgrounds of our pretrial adolescents were highly troublesome. Findings from studies investigating adverse childhood experiences indicate that they are highly correlated with each other [65], and various kinds of maltreatment are usually experienced simultaneously [66], as was the case here. Compared with a Finnish patient sample collected from one of the two national forensic units treating adolescents with severe mental disorders and violent behaviors [67], the families of pretrial offenders were even more commonly characterized by parental divorce, substance use, and criminality, suggesting an intergenerational cycle of criminality. Despite having being in contact with child welfare services, the offender sample had less commonly been institutionalized or placed in foster homes than the patient sample, so they most probably had been exposed for longer to harmful adverse childhood experiences.

Focusing on gender differences in background variables, only victimization by sexual abuse reached statistical significance. In fact, more than one in three girls, but none of the boys had reported sexual abuse in childhood, which is in line with earlier research reporting that subjection to sexual abuse is more common among female than male young offenders [68]. Victimization by sexual abuse in childhood is associated with a variety of emotional and behavioral problems, including violence, in both population and institutionalized samples [68-71]. It predisposes to repeated sexual trauma, drifting repeatedly into emotionally unsatisfactory and abusive relationships, and being incapable of protecting oneself from sexual health problems [72]. The violently offending girls in this sample indeed displayed unstable interpersonal relationships as well as impersonal sexual behavior more commonly than boys. Odgers et al. [73] have suggested that among high-risk girls victimization by abuse might be a better predictor for future violence than psychopathic traits, and that victimization may actually be an etiological factor for elevated psychopathic traits, or traits that mimic psychopathy (particularly deficient affect). Our findings support this speculation, and suggest that victimization in the sexual domain could be particularly distorting for female adolescent development.

Alcohol use disorders were common in our sample, and the majority of adolescents committed the index crime under the influence of alcohol, which is known to characterize Finnish homicide crimes performed by both adults [74] and adolescents [16]. Boys were, however, significantly more often than girls under alcohol intoxication during the index crime. This same gender difference has been reported in adults [75]. In line with the reports from the Institute of Criminology and Legal Policy in Finland $[76,77]$, victims of girls were often family members or current or previous intimates, and, respectively, those of boys were strangers. It is known that women typically carry out their crime in the context of home, and the violence is bound to their close relationships $[75,78]$. To conclude, gender differences observed in our sample resemble in many ways those reported in adult offenders.

\section{Strengths and limitations}

As far as the authors know, this is the first study to explore gender differences on psychopathic traits in girls and boys matched for both age and crime. The main strength of this study was its nationwide and comprehensive nature. The Finnish tradition of thorough forensic psychiatric examinations and reliable statistics form a solid basis for register-based studies. In Finland, the clearance rate for violent crimes is high; for example, the mean clearance rate for homicides during 1995-2004 was $92 \%$ [79]. The proportion of females in our sample corresponds quite well with proportion of females in violent crimes, as reported in national statistics of police investigated crime and selfreported juvenile delinquency [77]. The assessments were performed with the PCL-YV, which is regarded as a gold standard for assessing adolescent psychopathic traits. It is a time-consuming method demanding rigorous training, but is more objective than self-report instruments, which are more or less transparent, and thus, inadequate in studying offender populations [80, 81]. Unfortunately, it was not possible to estimate the representativeness of our sample by comparing the number of girls who underwent the pretrial examination with the overall number of girls with violent offending during the 31-year period. However, a previous Finnish study estimated that approximately $60 \%$ of 15 - to 17-year-old homicide suspects undergo forensic psychiatric examination [82]. Regardless of the fact that the sample contained all Finnish under aged girls who underwent a forensic psychiatric examination during the 31-year period, the sample size remained small. Despite the high quality and reliability of Finnish forensic psychiatric examinations, the data is not collected primarily for research purposes. The information is not written down in any systematic manner. This means that it was not possible to infer reliably whether the missing data indicated that the variable was actually absent or that the presence of the variable was not written down in the statement. One possible methodological problem is the use of self-reports and reports from relatives in the forensic psychiatric examination statements. Examinees and parents might be reluctant to correctly report adverse 
conditions or odd behaviors from offender's childhood. This might lead to under detection of, for example, incidences of mental illness or criminality in the family [83]. On the other hand, as Cannon et al. [84] pointed out, there might be a problem with recall bias when using retrospective data such as mother's knowledge of child's early development: the knowledge of child's adult outcome may influence memories of childhood behavior. Despite these obvious limitations, however, forensic psychiatric examinations are a unique source of information in research on psychopathology and criminality. Taking into account the small sample size, we did not use corrections for multiple testing, but, instead, effects sizes were calculated. With small sample sizes, a difference may be clinically meaningful despite failing to achieve statistical significance. In this study, the fairy large effect sizes hint to this possibility.

\section{Conclusion}

Although violently offending girls and boys did not differ in psychopathy total scores, significant gender differences existed on underlying factor and item scores as well as in background- and offence-related variables. Girls were less antisocial, but their relationships were more unstable, and their violence was bound to their close relationships. They also more often reported a history of child sexual abuse. Interventions with violent girls should focus on sexual trauma, appropriate and constructive skills to protect oneself against sexual abuse, and social skills in intimate relationships.

\section{Authors' contributions}

$\mathrm{NL}$ collected the data and worked as the first author, SO and JM performed statistical analyses, RKH planned the study protocol with NL and all authors participated in the writing process. All authors read and approved the final manuscript.

\section{Author details \\ ${ }^{1}$ Forensic Psychiatry, Helsinki University and Helsinki University Hospital, Helsinki, Finland. ${ }^{2}$ Psychiatry, Helsinki University and Helsinki University Hos- pital, Helsinki, Finland. ${ }^{3}$ Research Unit for Clinical Neuroscience, Department of Psychiatry, University of Oulu and Oulu University Hospital, Oulu, Finland. ${ }^{4}$ Medical Research Center Oulu, Oulu University Hospital and University of Oulu, Oulu, Finland. ${ }^{5}$ Center for Life Course Health Research, University of Oulu, Oulu, Finland. ${ }^{6}$ Adolescent Psychiatry, Tampere University and Tam- pere University Hospital, Tampere, Finland. ${ }^{7}$ Kellokoski Hospital, Vanha Valtatie 198, 04500 Kellokoski, Finland. ${ }^{8}$ Vanha Vaasa Hospital, Vaasa, Finland.}

\section{Acknowledgements}

We would like to acknowledge Adjunct professor Pekka Tani for co-operation as well as the authorities of the Department of Psychiatry, Helsinki University Hospital, and Kellokoski Hospital.

\section{Competing interests}

The authors declare that they have no competing interests.

\section{Funding}

This study has been funded by the Helsinki and Uusimaa Hospital District and Academy of Finland (\#268336), however, the funders have had no role in study design, data collection and analysis, decision to publish, or preparation of the manuscript.
Received: 24 November 2015 Accepted: 12 October 2016

Published online: 01 November 2016

\section{References}

1. Hare RD. Psychopathy, affect, and behavior. In: Cooke DJ, Forth AE, Hare RD, editors. Psychopathy: theory, research, and implications for society. Dordrecht: Kluwer; 1998.

2. Benning SD, Patrick CJ, Blonigen DM, Hicks BM, lacono WG. Estimating facets of psychopathy from normal personality traits: a step toward community epidemiological investigations. Assessment. 2005;12:3-18.

3. American Psychiatric Association. Diagnostic and statistical manual of mental disorders. 5th ed. Washington: American Psychiatric Press; 2013.

4. Frick PJ, Ray JV, Thornton LC, Kahn RE. A developmental psychopathology approach to understanding callous-unemotional traits in children and adolescents with serious conduct problems. J Child Psychol Psychiatr. 2014;55:532-48.

5. Loney BR, Taylor J, Butler MA, lacono WG. Adolescent psychopathy features: 6-year temporal stability and the prediction of externalizing symptoms during the transition to adulthood. Aggress Behav. 2007:33:242-52.

6. Frick PJ, Ray JV, Thornton LC, Kahn RE. A developmental psychopathology approach to understanding callous-unemotional traits in children and adolescents with serious conduct problems. J Child Psychol Psychiatry. 2014;55:532-48.

7. Verona E, Sadeh N, Javdani S. The influences of gender and culture on child and adolescent psychopathy. In: Salekin RT, Lynam DR, editors. Handbook of child and adolescent psychopathy. New York: The Guilford Press; 2010.

8. Schrum CL, Salekin RT. Psychopathy in adolescent female offenders: an item response theory analysis of the psychopathy checklist: youth version. Behav Sci Law. 2006;24:39-63.

9. Anderson NE, Kiehl KA. Psychopathy: developmental perspectives and their implications for treatment. Restor Neurol Neurosci. 2014;32:103-17.

10. Daversa MT. Early environmental predictors of the affective and interpersonal constructs of psychopathy. Int J Offender Ther Comp Criminol. 2010;54:6-21

11. Farrington DP, Ullrich S, Salekin RT. Environmental influences on child and adolescent psychopathy. In: Salekin RT, Lynam DR, editors. Handbook of child and adolescent psychopathy. New York: The Guilford Press; 2010

12. Gao Y, Raine A, Chan F, Venables PH, Mednick SA. Early maternal and paternal bonding, childhood physical abuse and adult psychopathic personality. Psychol Med. 2010;40:1007-16.

13. Hawes DJ, Dadds MR, Frost AD, Hasking PA. Do childhood callous-unemotional traits drive change in parenting practices? J Clin Child Adolesc Psychol. 2011;40:507-18.

14. Kimonis ER, Cross B, Howard A, Donoghue K. Maternal care, maltreatment and callous-unemotional traits among urban male juvenile offenders. J Youth Adolesc. 2013;42:165-77.

15. Kimonis ER, Centifanti LC, Allen JL, Frick PJ. Reciprocal influences between negative life events and callous-unemotional traits. J Abnorm Child Psychol. 2014;42:1287-98.

16. Lindberg N, Laajasalo T, Holi M, Putkonen H, Weizmann-Henelius G, Häkkänen-Nyholm H. Psychopathic traits and offender characteristics-a nationwide consecutive sample of homicidal male adolescents. BMC Psychiatry. 2009;9:18.

17. Rubio JS, Krieger MA, Finney EJ, Coker KL. A review of the relationship between sociocultural factors and juvenile psychopathy. Aggress Violent Behav. 2014;19:23-31.

18. Viding E, Frick PJ, Plomin R. Aetiology of the relationship between callousunemotional traits and conduct problems in childhood. Br J Psychiatry Suppl. 2007:49:33-8.

19. Fontaine NM, Rijsdijk FV, McCrory EJ, Viding E. Etiology of different developmental trajectories of callous-unemotional traits. J Am Acad Child Adolesc Psychiatry. 2010:49:656-64.

20. Bezdjian S, Raine A, Baker LA, Lynam DR. Psychopathic personality in children: genetic and environmental contributions. Psychol Med. 2011:41:589-600. 
21. Krischer MK, Sevecke K. Early traumatization and psychopathy in female and male juvenile offenders. Int J Law Psychiatry. 2008;31:253-62.

22. Ficks CA, Dong L, Waldman ID. Sex differences in the etiology of psychopathic traits in youth. J Abnorm Psychol. 2014;123:406-11.

23. Forth $A E$, Burke HC. Psychopathy in adolescence: assessment, violence, and developmental precursors. In: Cooke DJ, Forth AE, Hare RD, editors. Psychopathy: theory, research, and implications for society. Dordrecht: Kluver; 1998.

24. Frick PJ, Cornell AH, Bodin SD, Dane HA, Barry CT, Loney RB. Callousunemotional traits and developmental pathways to severe conduct problems. Dev Psychol. 2003;39:246-60.

25. Gretton H, McBride M, Hare RD, O'Shaughnessy R, Kumka G. Psychopathy and recidivism in adolescent sex offenders. Crim Justice Behav. 2001;28:427-49.

26. Langstrom N, Grann M. Psychopathy and violent recidivism among young criminal offenders. Acta Psychiatr Scand Suppl. 2002;412:86-92.

27. Murrie DC, Cornell DG, Kaplan S, McConville D, Levy-Elkon A. Psychopathy scores and violence among juvenile offenders: a multi-measure study. Behav Sci Law. 2004;22:49-67.

28. Kruh IP, Frick PJ, Clements CB. Historical and personality correlates to the violence patterns of juveniles tried as adults. Crim Justice Behav. 2005;32:69-96.

29. Thornton LC, Frick PJ, Shulman EP, Ray JV, Steinberg L, Cauffman E. Callous-unemotional traits and adolescents' role in group crime. Law Hum Behav. 2015;39:368-77.

30. Miller DJ, Watts A, Jones SE. Does psychopathy manifest divergent relations with components of its nomological network depending on gender? Pers Individ Dif. 2011;50:264-9.

31. Salekin RT. Psychopathy in children and adolescents. In: Patrick CJ, editor. Handbook of psychopathy. New York: Guilford Press; 2006.

32. Moretti MM, Catspole RE, Odgers C. The dark side of girlhood: recent trends, risk factors and trajectories to aggression and violence. Can Child Adolesc Psychiatr Rev. 2005;14:21-5.

33. Campbell MA, Porter S, Santor D. Psychopathic traits in adolescent offenders: an evaluation to criminal history, clinical, and psychosocial correlates. Behav Sci Law. 2004;22:23-47.

34. Salekin RT, Leistico AM, Trobst KK, Schrum CL, Lochman JE. Adolescent psychopathy and personality theory- the interpersonal circumplex: expanding evidence of a nomological net. J Abnorm Child Psychol. 2005:33:445-60

35. Sevecke K, Kosson DS, Krischer MK. The relationship between attention deficit hyperactivity disorder, conduct disorder, and psychopathy in adolescent male and female detainees. Behav Sci Law. 2009;27:577-98.

36. Penney SR, Moretti MM. The relation of psychopathy to concurrent aggression and antisocial behavior in high-risk adolescent girls and boys. Behav Sci Law. 2007:25:21-41.

37. Eronen $M$, Repo E, Vartiainen $H$, Tiihonen J. Forensic Psychiatric Organization in Finland. Int J Law Psychiatry. 2000;23:541-6.

38. World Health Organization. Manual of the International statistical classification of diseases, injuries, and causes of death. 8th ed. Geneva: World Health Organization; 1962.

39. American Psychiatric Association. Diagnostic and statistical manual of mental disorders. 3rd ed. Washington: American psychiatric Press; 1987.

40. World Health Organization. The ICD-10 classification of mental and behavioural disorders: clinical descriptions and diagnostic guidelines. Geneva: World Health Organization; 1992.

41. Forth AE, Kosson DS, Hare RD. The Hare PCL:YV. Toronto: Multi-Health Systems; 2003.

42. Hare RD. The hare psychopathy checklist—revised. Toronto: Multi-Health Systems; 1991.

43. Hare RD. The hare psychopathy checklist—revised. 2nd ed. Toronto: Multi-Health Systems; 2003.

44. Cooke DJ, Michie C. Psychopathy across cultures: North America and Scotland compared. J Abnorm Psychol. 1999;108:58-68.

45. Hare RD, Clark D, Grann M, Thornton D. Psychopathy and the predictive validity of the PCL-R: an international perspective. Behav Sci Law. 2000;18:623-45.

46. Sullivan EA, Abramowitz CS, Lopez M, Kosson DS. Reliability and construct validity of the psychopathy checklist -revised for Latino, European American, and African American male inmates. Psychol Assess. 2006;18:382-92.
47. Putkonen H, Weizmann-Henelius G, Repo-Tiihonen E, Lindberg N, Saarela T, Eronen M, Häkkänen-Nyholm H. Homicide, psychopathy, and aging - a nationwide register-based case-comparison study of homicide offenders aged 60 years or older. J Forensic Sci. 2010;55:1552-6.

48. Rasmussen K, Storsaeter O, Levander S. Personality disorders, psychopathy, and crime in a Norwegian prison population. Int J Law Psychiatry. 1999;22:91-7.

49. Thomson A, Tiihonen J, Miettunen J, Sailas E, Virkkunen M, Lindberg N. Psychopathic traits among a consecutive sample of Finnish pretrial firesetting offenders. BMC Psychiatry. 2015;15:44.

50. Woodworth M, Porter S. In cold blood: characteristics of criminal homicides as a function of psychopathy. J Abnorm Psychol. 2002;111:436-45.

51. Alterman Al, Cacciola JS, Rutherford MJ. Reliability of the revised psychopathy checklist in substance abuse patients. Psychol Assess. 1993;5:442-8.

52. Grann M, Langstrom N, Tengstrom A, Stalenheim E. Reliability of filebased retrospective ratings of psychopathy with the PCL-R.J Pers Assess. 1998:70:416-26.

53. Mossman D. Assessing predictions of violence: being accurate about accuracy. J Consult Clin Psychol. 1994;62:783-92.

54. Wong S. Is Hare's psychopathy checklist reliable without the interview? Psychol Rep. 1988;62:931-4

55. Brandt JR, Wallace A, Kennedy CJ, Curtin JJ. Assessment of psychopathy in a population of incarcerated adolescent offenders. Psychol Assess. 1997;9:429-35

56. Catschpole EH, Gretton HM. The predictive validity of risk assessment with violent young offenders: a 1-year examination of criminal outcome. Crim Justice Behav. 2003;30:688-707.

57. Gretton H, Hare RD, Catchpole R. Psychopathy and offending from adolescence to adulthood: a 10-year follow-up. J Consult Clin Psychol. 2004;72:636-45.

58. O'Neill ML, Lidz V, Heilbrun K. Adolescents with psychopathic characteristics in a substance abusing cohort: treatment process and outcomes. Law Hum Behav. 2003;27:299-313.

59. Cohen J. A coefficient of agreement for nominal scales. Educ Psychol Meas. 1960;20:37-46.

60. Landis JR, Koch GG. The measurement of observer agreement for categorical data. Biometrics. 1977;33:159-74.

61. Cohen J. A power primer. Psychol Bull. 1992;112:155-9.

62. Nee C, Farman S. Female prisoners with borderline personality disorder: some promising treatment developments. Crim Behav Ment Health. 2005;15:2-16.

63. Sprague J, Javdani S, Sadeh N, Newman JP, Verona E. Borderline personality disorder as a female phenotypic expression of psychopathy? Personal Disord. 2012;3:127-39.

64. Decuyper M, Colins OF, De Clerca B, Vermeiren R, Broekaert E, Bijttebier P, et al. Latent personality profiles and the relations with psychopathology and psychopathic traits in detained adolescents. Child Psychiatry Hum Dev. 2013;44:217-32

65. Felitti VJ, Anda RF, Nordenberg D, Williamson DF, Spitz AM, Edwards V, Koss MP, Marks JS. Relationship of childhood abuse and household dysfunction to many of the leading causes of death in adults. The adverse childhood experiences (ACE) study. Am J Prev Med. 1998;14:245-58.

66. Dong M, Anda RF, Felitti VJ, Dube SR, Williamson DF, Thompson TJ, Giles WH. The interrelatedness of multiple forms of childhood abuse, neglect, and household dysfunction. Child Abuse Negl. 2004;28:771-84.

67. Kaltiala-Heino R, Eronen M, Putkonen H. Violent girls in adolescent forensic care are more often psychotic and traumatized than boys in the same level of care. J Forens Psychiatry Psychol. 2014. doi:10.1080/14789949.201 4.943795 (Published online 12 Aug 2014).

68. Gore-Felton C, Koopman C, McGarvey E, Hernanzed N, Canterbury RJ. Relationships of sexual, physical, and emotional abuse to emotional and behavioral problems among incarcerated adolescents. J Child Sex Abus. 2001;10:73-88

69. Cutajar MC, Mullen PE, Ogloff JR, Thomas SD, Wells DL, Spataro J. Psychopathology in a large cohort of sexually abused children followed up to 43 years. Child Abuse Negl. 2010;34:813-22.

70. Gammelgard M, Weizmann-Henelius G, Koivisto A, Eronen M, KaltialaHeino R. Gender differences in violence risk profiles. J Forens Psychiatry Psychol. 2012;23:76-94. 
71. Scott KM, Smith DR, Ellis PM. Prospectively ascertained child maltreatment and its association with DSM-IV mental disorders in young adults. Arch Gen Psychiatry. 2010;67:712-9.

72. Saewyc EM, Magee LL, Pettingell SE. Teenage pregnancy and associated risk behaviors and sexually abused adolescents. Perspect Sex Reprod Health. 2004;36:98-105.

73. Odgers CL, Repucci ND, Moretti M. Nipping psychopathy in the Bud: an examination of the convergent, predictive and theoretical utility of the PCL-YV among adolescent girls. Behav Sci Law. 2005;23:743-63.

74. Häkkänen-Nyholm H, Putkonen H, Lindberg N, Holi M, Rovamo T, Weizmann-Henelius $G_{\text {, }}$ Gender differences in Finnish homicide offence characteristics. Forensic Sci Int. 2009;186:75-80.

75. Robbins PC, Monahan J, Silver E. Mental disorder, violence and gender. Law Hum Behav. 2003;27:561-71.

76. Lehti M. Nuorten henkirikokset 1980-2004. In: Honkatukia P, Kivivuori J, editors. Nuorisorikollisuus: määrä, syyt ja kontrolli. Oikeuspoliittisen tutkimuslaitoksen julkaisuja 221. Helsinki: Oikeuspoliittinen tutkimuslaitos; 2006.

77. Rikollisuustilanne 2014. Katsauksia 4/2015. Helsinki: Helsingin yliopisto, Kriminologian ja oikeuspolitiikan instituutti; 2015.

78. Magdol L, Moffitt TE, Caspi A, Newman DL, Fagan J, Silva PA. Gender differences in partner violence in a birth cohort of 21-year-olds: bridging the gap between clinical and epidemiological approaches. J Consult Clin Psychol. 1997;65:68-78.
79. National Statistics. 2007. http://www.statistics.gov.uk/cci/nugget. asp?|D=6.

80. Boonmann C, Jansen LM, Lisette A, Vahl P, Hillege SL, Doreleijers TA, Vermeiren RR. Self-reported psychopathic traits in sexually offending juveniles compared with generally offending juveniles and general population youth. Int J Offender Ther Comp Criminol. 2015;59:85-95.

81. Vitacco MJ, Salekin RT, Rogers R. Forensic issues for child and adolescent psychiatry. In: Salekin RT, Lynam DR, editors. Handbook of child and adolescent psychopathy. New York: The Guilford Press; 2010.

82. Hagelstam C, Häkkänen H. Adolescent homicides in Finland: offence and offender characteristics. Forensic Sci Int. 2006;164:110-5.

83. Laajasalo T, Häkkänen H. Backgroud characteristics of mentally ill homicide offenders - a comparison of five diagnostic groups. J Forensic Psychol Psychiatr. 2004;15:451-74

84. Cannon M, Jones P, Huttunen M, Tanskanen A, Huttunen T, Rabe-Hesketh $S$, et al. School performance in Finnish children and later development of schizophrenia. A population-based longitudinal study. Arch Gen Psychiatry. 1999;56:457-63.

\section{Submit your next manuscript to BioMed Central and we will help you at every step:}

- We accept pre-submission inquiries

- Our selector tool helps you to find the most relevant journal

- We provide round the clock customer support

- Convenient online submission

- Thorough peer review

- Inclusion in PubMed and all major indexing services

- Maximum visibility for your research

Submit your manuscript at www.biomedcentral com/submit 